\title{
Legume intake and risk of type 2 diabetes in British women
}

\author{
M. Aldwairji, C. Orfila and V. J. Burley \\ School of Food Science and Nutrition, University of Leeds, Leeds, LS2 9JT, UK
}

Legume consumption is variable between European countries, with intakes tending to be relatively low overall. ${ }^{(1)}$ Very few prospective studies have examined the association between legume intake and risk of type 2 diabetes (T2DM) ${ }^{(2)}$. The aim of this study is to determine the relationship between legume intake and risk of T2DM among British women. The UK Women Cohort's Study is a population-based prospective cohort of middle-aged women. From 35,372 women who completed a 217-item food frequency questionnaire (FFQ), 12,149 women also completed a follow-up questionnaire after an average of 4 years. Participants who reported a history of diabetes at baseline and those with unfeasible energy intakes were excluded from the study leaving 114 women who reported having developed diabetes during the follow-up period and 11,982 women who remained free from diabetes. Average daily legume intake expressed as grams per day was calculated from ten food items listed in the baseline food frequency questionnaire. Dried legumes included boiled or canned legumes that had previously been dried, such as lentils, chickpeas, mung beans, baked beans, hummus and red kidney beans while fresh legumes included fresh, frozen or canned garden peas and green beans (runner or French). Women were divided into intake tertiles by division of the whole cohort into 3 equal-sized groups. Lifestyle and other dietary covariates were derived from the baseline questionnaire. Logistic regression analysis was used to determine the relationship between legume consumption and risk of incident T2DM.

Table 1. Odds ratios and $95 \%$ confidence intervals of T2DM according to tertiles of total, dried and fresh legume intakes in 12,096 British women

\begin{tabular}{|c|c|c|c|c|c|}
\hline \multirow[b]{2}{*}{ Type } & \multicolumn{2}{|c|}{ Legume intake } & \multirow[b]{2}{*}{ T2DM Cases } & \multicolumn{2}{|c|}{ OR $(95 \% \mathrm{CI})$} \\
\hline & Tertile & $\overline{\text { Range g/day }}$ & & Age adjusted model & Full adjusted model \\
\hline$\overline{\text { Dried legumes }}$ & $\begin{array}{l}1 \\
2 \\
3 \\
P \text { for trend }\end{array}$ & $\begin{array}{l}<21.3 \\
21.3-41.9 \\
\geq 42 \\
114\end{array}$ & $\begin{array}{r}55 \\
22 \\
37 \\
<0.01\end{array}$ & $\begin{array}{l}1 \\
0.41(0.25,0.68) \\
0.72(0.47,1.12) \\
0.03\end{array}$ & $\begin{array}{l}1 \\
0.49(0.29,0.84) \\
0.85(0.52,0.84)\end{array}$ \\
\hline Fresh legumes & $\begin{array}{l}1 \\
2 \\
3 \\
P \text { for trend }\end{array}$ & $\begin{array}{l}<15 \\
15-37 \\
\geq 37 \\
114\end{array}$ & $\begin{array}{r}30 \\
42 \\
42 \\
0.46\end{array}$ & $\begin{array}{l}1 \\
1.31(0.82,2.1) \\
1.29(0.80,2.1) \\
0.27\end{array}$ & $\begin{array}{l}1 \\
1.41(0.84,2.37) \\
1.51(0.89,2.59)\end{array}$ \\
\hline Total legumes & $\begin{array}{l}1 \\
2 \\
3 \\
P \text { for trend }\end{array}$ & $\begin{array}{l}<46 \\
46-80 \\
\geq 80 \\
114\end{array}$ & $\begin{array}{r}38 \\
33 \\
43 \\
0.41\end{array}$ & $\begin{array}{l}1 \\
0.82(0.51,1.31) \\
1.12(0.71,1.74) \\
0.25\end{array}$ & $\begin{array}{l}1 \\
0.89(0.53,1.49) \\
1.33(0.80,2.22)\end{array}$ \\
\hline
\end{tabular}

Table 1 presents results from an age-adjusted and a multivariable-adjusted model which additionally included, energy intake, smoking status, adult weight change, socioeconomic status (professional, intermediate and manual), alcohol intake (g/day), physical activity level and family history of diabetes. Using both models, women in the highest two intake tertiles for dried legumes experienced significantly reduced odds of incident T2DM than women in the lowest intake category. In contrast, odds tended to be elevated in the higher consumption groups of fresh legumes, although this relationship was not statistically significant. These results support findings from an earlier observational study conducted in China that consumption of legumes, was inversely associated with the risk of type 2 diabetes ${ }^{(2)}$.

1. Schneider AV (2002) Br J Nutr 88, 243-250.

2. Villegas R, Gao YT, Yang G et al. (2008) Am J Clin Nutr 87, 162-167. 